\title{
Call for Special Issue Papers: Drugs and Disease Testing Model Systems
}

\section{Deadline for Manuscript Submission: October 1, 2020}

\author{
Guest Editors: Ying Chen, PhD; Tufts University, Boston, MA; Marianne Verhaar, MD, PhD; \\ Utrecht University Medical Center, The Netherlands
}

Research in engineered tissue model system focusing on stem cells and tissue engineered constructs for applications in regenerative medicine has driven the discovery and development of new drugs for human disease. In this issue, Tissue Engineering, Part $C$ will launch a Special Collection that highlights the contribution of model systems to the current discovery of innovative drugs across multiple disease areas. The Guest Editors of this Tissue Engineering, Part C special issue will consider articles from the full breadth of research in the field: from original research papers, reviews, and methods papers, to perspectives, profiles, commentaries, and exemplary front matter.

Areas of interest include, but are not limited to:

- Modeling human diseases using stem cells, scaffolds and growth factors

- Modeling human diseases using stem cells and "organs-on-a-chip" for drug discovery

- Applications of organoid-derived tissue models in drug discovery/ screening/delivery

- Applications of CRISPR/Cas9 modified induced pluripotent stem cells in disease model and tissue engineering

- Drug screening using human derived organoids

- Calibration and validation of organoid systems for drug screening applications

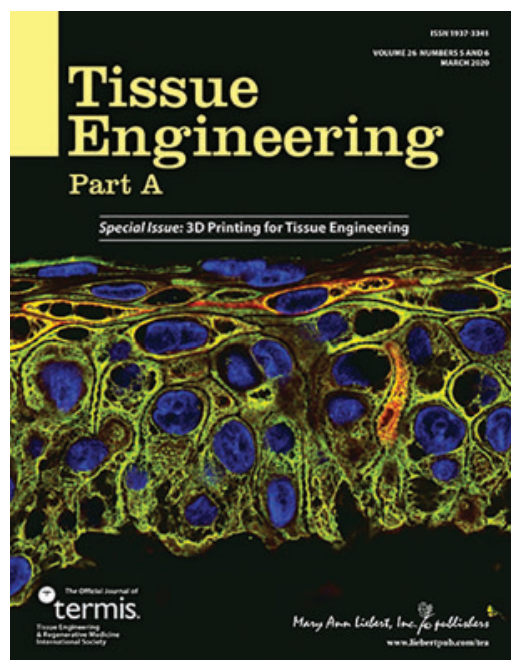

Contributions will receive prompt and thorough peer review. Please refer to our Instructions for Authors at www.liebertpub .com/ten before submitting your manuscript for consideration. Authors are encouraged to vet ideas directly with Drs. Chen and Verhaar via e-mail before submitting. Please submit all pre-submission inquiries to Dr. Chen at Ying.Chen @tufts.edu.

Tissue Engineering is a distinguished biomedical journal advancing the field with cutting-edge research and applications on all aspects of tissue growth and regeneration. This multidisciplinary journal brings together the principles of engineering and life sciences in tissue development and regenerative medicine.

Tissue Engineering is divided into three parts, providing a central forum for groundbreaking scientific research and developments of clinical applications from leading experts in the field that will enable contributions to the ultimate care of patients.

Manuscript Submission Deadline: October 1, 2020

Editorial questions?

Contact Dr. Ying Chen, Guest Editor, E-mail: ying.chen@tufts.edu

Contact Dr. Marianne Verhaar, Guest Editor, E-mail: m.c.verhaar@umcutrecht.nl

Visit the Instructions for Authors: www.liebertpub.com/ten

Submit your paper for peer review online:

https://mc.manuscriptcentral.com/ten 